\title{
A Case of Vaginal Leiomyoma: A Rare Entity
}

\author{
${ }^{1}$ Neeta Bansal, ${ }^{2}$ Vidushi Jyala Jain, ${ }^{3}$ Vineeta Gupta, ${ }^{4}$ Aparna Bharadwaj
}

\begin{abstract}
Although uterine fibroids are common, vaginal fibroids are very rare. We report one such rare case of a woman who presented with a big mass projecting in the vagina with complaints of dyspareunia, dysuria and passage of dark, altered collected blood per vaginum. Ultrasound and magnetic resonance imaging (MRI) reported it as a cervical fibroid. It was enucleated successfully through vaginal route and histopathology report confirmed diagnosis of benign vaginal leiomyoma. Diagnosis of vaginal leiomyoma is rather challenging and its complete removal should be done to prevent recurrence, rule out sarcomatous change and relieve symptoms.
\end{abstract}

Keywords: Vaginal leiomyoma, Vaginal myomectomy, Vaginal leiomyosarcoma.

How to cite this article: Bansal N, Jain VJ, Gupta V, Bharadwaj A. A Case of Vaginal Leiomyoma: A Rare Entity. J South Asian Feder Obst Gynae 2015;7(3):231-233.

\section{Source of support: Nil}

Conflict of interest: None

Date of received: 13 July 2015

Date of acceptance: 18 September 2015

Date of publication: December 2015

\section{INTRODUCTION}

Uterine leiomyoma is a common gynecological disorder seen in the reproductive age group but vaginal leiomyoma is a rare occurrence and this case report will contribute to its literature. Cervical fibroids account for only 1 to $4 \%$ of all cases and primary vaginal fibroids are even rarer. ${ }^{1}$ They are commonly seen in the age group ranging from 35 to 50 years and are usually solitary and not associated with leiomyomas elsewhere in the body. Diagnosis is challenging and histopathology clinches the diagnosis.

\footnotetext{
${ }^{1}$ Associate Professor, ${ }^{2,4}$ Assistant Professor

${ }^{3}$ Professor and Head

1-3Department of Obstetrics and Gynecology, Shri Guru Ram Rai Institute of Medical and Health Sciences, Dehradun Uttarakhand, India

${ }^{4}$ Department of Pathology, Shri Guru Ram Rai Institute of Medical and Health Sciences, Dehradun, Uttarakhand, India

Corresponding Author: Neeta Bansal, Associate Professor, Department of Obstetrics and Gynecology, Shri Guru Ram Rai Institute of Medical and Health Sciences Dehradun, Uttarakhand, India, Phone: 09410320555, e-mail: vidushijyala55@gmail.com
}

We report a case of vaginal leiomyoma which was initially reported as a cervical fibroid.

\section{CASE REPORT}

We report a case of a 40 years old female P1A1 who presented with a mass per vaginum for past 5 years. She had complaints of dyspareunia, discharge per vaginum, dysuria, incomplete voiding and feeling of pressure over the bladder since 5 years. For last 1 month, she had complaints of irregular bouts of dark, altered colored vaginal bleeding. She had a female child by lower segment cesarian section (LSCS) 12 years back for transverse lie and had one abortion about 10 years back.

On examination, her vitals were stable. On per abdominal examination, abdomen was soft, nontender and no mass felt. On per speculum examination, a huge mass was seen arising from the anterior vaginal wall while cervix could not be visualized. On palpation a smooth, round mass measuring $10 \times 8 \mathrm{~cm}$ in diameter was felt arising from the right anterolateral wall of vagina (Fig. 1). Upper limit of the mass could not be delineated. It was firm, nontender with restricted mobility. The mass had pushed the cervix high up laterally. Uterus size could not be assessed due to the vaginal mass.

On ultrasound, $10 \times 8 \mathrm{~cm}$ hypoechoic mass was seen in upper part of vagina suggestive of a pedunculated cervical fibroid. Magnetic resonance imaging (MRI) was done which too suggested a cervical fibroid.

The tumor was enucleated completely through the vaginal route (Fig. 2). It was completely confined to the vagina and the cervix appeared free. Microscopic

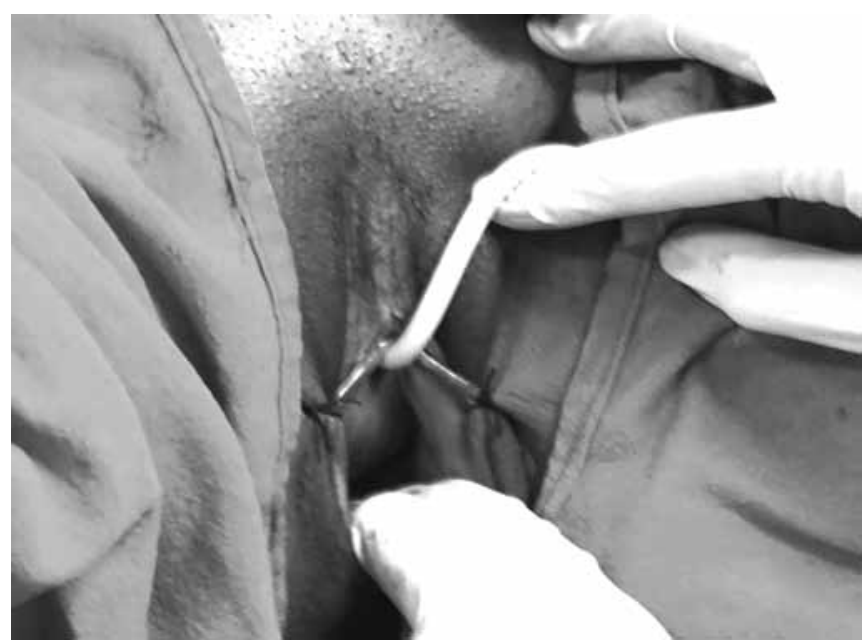

Fig. 1: Mass protruding from the anterolateral vaginal wall 


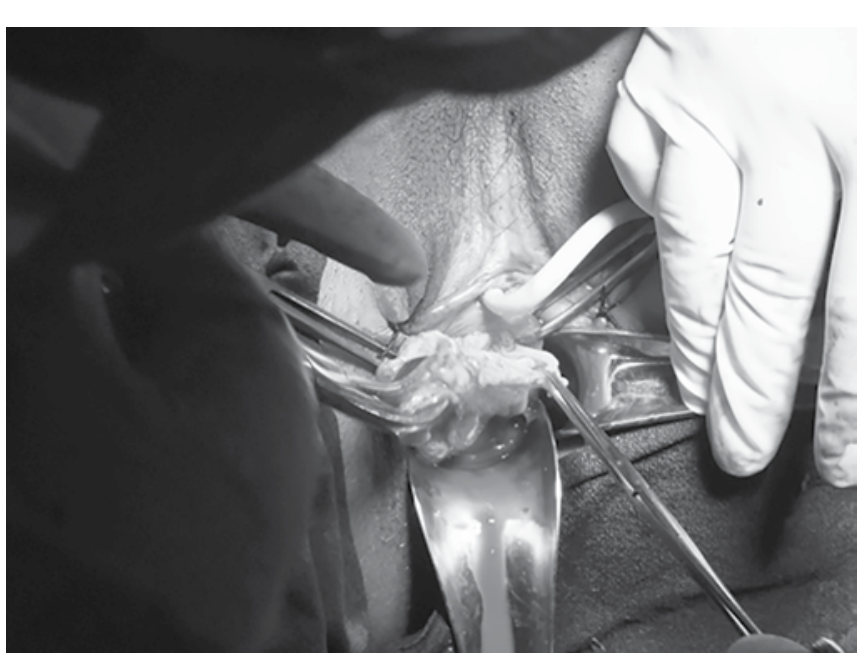

Fig. 2: Removal of degenerated vaginal leiomyoma

examination revealed well circumscribed vaginal leiomyoma with foci of necrosis and myxoid degeneration (Fig. 3). Hysterectomy was not performed as patient had no menstrual symptoms. Postoperative period was uneventful and patient discharged in satisfactory condition.

\section{DISCUSSION}

Vaginal tumors are rare and include papilloma, hemangioma, mucus polyp and rarely leiomyoma. So far about 300 cases of vaginal leiomyomas have been reported in literature since the first detected case way back in 1733 by Denys de Leyden. ${ }^{2} \mathrm{~A}$ few more case reports have been published recently with varied presentations.

Vaginal leiomyomas are commonly seen in 30 to 50 years age group. Cases have been reported in posthysterectomized as well as in postmenopausal women. ${ }^{3}$ They usually present as a single well circumscribed mass arising from the anterior vaginal wall. Patient may be asymptomatic initially. Symptoms are due to the mass effect and depend on the location of the mass. They include lower abdominal pain, backache, dyspareunia, urinary retention, dysuria and menstrual abnormalities. Leron and Stanton reported a case of vaginal leiomyoma with symptoms of prolapse and urge incontinence. ${ }^{4}$ Diagnosis by ultrasound and MRI may not be conclusive and vaginal fibroids are often wrongly reported as cervical fibroids or ovarian mass. A case of vaginal fibroid was reported which presented as a huge ovarian tumor in a postmenopausal lady, where diagnosis was confirmed only on laparotomy and histopathology. ${ }^{3}$ Gowri et al have reported a case where a vaginal leiomyoma presented as a gluteal abscess with pus draining in the vagina. ${ }^{5}$ Wide spectrum of symptom complex creates a clinical dilemma in diagnosis of vaginal leiomyoma.



Fig. 3: Microphotograph showing leiomyoma (upper arrow) with vaginal mucosa (lower arrow)

The case reported here was diagnosed as a cervical fibroid on sonography and MRI. Examination too was not conclusive as the upper limit could not be reached. Decision of enucleation of the mass by vaginal route was taken. During surgery, the leiomyoma was found to be confined to the vaginal wall and the cervix could be seen separately.

The most effective approach to surgery depends on the size and location of the fibroid. This is either by abdominal or vaginal route. At times in some cases even an abdominoperineal approach may have to be employed.

The tumor must be removed enmass to prevent recurrence and for fear of malignant transformations. ${ }^{5}$ These tumors are usually benign but leiomyoma of the vagina may undergo malignant change to become borderline malignancy or leiomyosarcoma. Omer Cobanoglu et al have reported a case where, after excision, a vaginal leiomyoma was diagnosed as malignant on biopsy. The patient then underwent total abdominal hysterectomy, bilateral salpingo-oophorectomy and total vaginectomy followed by chemotherapy, but died after 5 months due to recurrence. ${ }^{6}$

Gupta et al reported an unusual case of vaginal fibroid presenting as an ovarian tumor in a postmenopausal lady and excision of the fibroid was done along with hysterectomy. ${ }^{3}$ Thus, the approach to surgery and the need for hysterectomy in perimenopausal age group depends on the individual patient profile.

\section{CONCLUSION}

Benign vaginal leiomyoma may present as a vaginal mass with pressure symptoms or with varied presentation in different age groups. They should be excised completely to prevent sarcomatous change and recurrence. Enucleation and histopathological examination of 
vaginal leiomyomas should be done in all cases while in perimenopausal and postmenopausal age group hysterectomy may be required.

\section{REFERENCES}

1. Padubidri G, Daftary SN. Fibromyomas of the uterus and uterine polyps. Shaw's Textbook of gynaecology. 14th ed. New Delhi Elsevier; 2008. p. 315-328.

2. Young SB, Rose PG, Reuter KL. Vaginal fibromyomata: Two cases with preoperative assessment. Obstet Gynecol 1991 Nov;78(5 Pt 2):972-974.
3. Vineeta G, Arya P, Vandana G, Rawat DS. A rare case of vaginal fibroid presenting as ovarian tumor. J Obstet Gynaecol India 2006;56:537-538.

4. Leron E, Stanton SL. Vaginal leiomyoma-an imitator of prolapsed. Int Urogynecol J Pelvic Floor Dysfunction 2000; 11:196-198.

5. Gowri R, Soundararaghavan S, Oumachigui A, Sistla SC, Iyengar KR. Leiomyoma of the vagina: an unusual presentation. J Obstet Gynaecol Res 2003;29:395-398.

6. Cobanoglu O, Gurkan Zorlu C, Ergun Y, Kutluay L. Leiomyosarcoma of the vagina. Eur J Obstet Gynecol 1996;70: 205-220. 